\title{
Colostro Fermentado, Associado ao Óleo de Soja e Promotor de Crescimento, em Substituição ao Leite, na Alimentação de Bezerros Mestiços Leiteiros ${ }^{1}$
}

\author{
Antonio Bento Mancio², Rafael Henrique de Tonissi e Buschinelli de Goes ${ }^{3}$, Álvaro Luiz Marinho \\ Castro $^{4}$, Oriel Fajardo Campos ${ }^{5}$, Paulo Roberto Cecon ${ }^{6}$, Alonso Thiago Silvestre da Silva ${ }^{7}$
}

\begin{abstract}
RESUMO - Objetivou-se avaliar o desempenho de 40 bezerros F1 Holandês x Gir com peso médio de 36 kg, provenientes de rebanhos leiteiros alimentados com leite integral ou colostro fermentado, associado ou não com óleo de soja, com ou sem promotor de crescimento (Zeranol). Foram avaliados o ganho de peso, a circunferência torácica, altura de cernelha dos animais, o consumo de leite ou de colostro fermentado e o consumo de ração concentrada, entre o $15 \underline{0}$ e $60^{\circ}$ dia de idade. A utilização de Zeranol não promoveu diferença no consumo de ração concentrada quando se utilizou leite integral. Os animais que receberam colostro fermentado mais promotor de crescimento apresentaram consumo de ração concentrada 44,23\% maior que aqueles sem promotor de crescimento e $132 \%$ superior ao dos animais alimentados com leite integral e Zeranol. Para ganho de peso, não houve efeito entre as associações de óleo de soja e Zeranol. Os bezerros do tratamento com leite e Zeranol apresentaram maior altura de cernelha $(-85,70 \mathrm{~cm})$. A utilização de óleo de soja ou de Zeranol não influenciou a circunferência torácica (média de 88,19 cm). Os bezerros submetidos aos dois tipos de dieta líquida apresentaram taxa de crescimento constante e semelhante, demonstrando que o colostro fermentado é capaz de promover ganhos de peso da mesma magnitude que o leite integral.
\end{abstract}

Palavras-chave: altura de cernelha, circunferência torácica, colostro, leite integral, óleo de soja, Zeranol

\section{Effects of Replacing Milk with Fermented Colostrum, with or without Soy Oil and Growth Promoter for Crossbred Dairy Calves}

\begin{abstract}
The objective of this trial was to study the effects of replacing milk with whole milk or fermented colostrum, supplemented or not with soy oil and with or without growth promoter (Zeranol) on performance of 40 F1 Holstein x Gir calves averaging $36 \mathrm{~kg}$. Weight gain, thoracic circumference, withers height and milk or fermented colostrums intake, and concentrated ration intake were the variables investigated from age 15 to 60 days. No significant difference on feed intake was observed when whole milk and Zeranol were fed. Feed intake of animals fed fermented colostrum with Zeranol increased by $44.23 \%$ than those without Zeranol and by $132 \%$ than those fed whole milk with Zeranol. No effects of feeding soy oil with Zeranol on gain weight was detected. Calves fed milk and Zeranol had greater withers height $(85.70 \mathrm{~cm})$. Supplementation of the liquid diet with soy oil and with Zeranol did not change thoracic circumference (average of $88.19 \mathrm{~cm}$ ). Calves fed both liquid diet showed constant and similar growth rate. Fermented colostrumbased diet can promote the same weight gain as whole milk-based diet.
\end{abstract}

Key Words: colostrum, whole milk, soy oil, thorax circumference, withers height, Zeranol

\section{Introdução}

O número de vacas com grau de sangue holandês vem crescendo nos últimos anos. Considerando-se que $50 \%$ das crias desses animais são machos, com taxa de sobrevivência de $80 \%$, estima-se que aproximadamente 3,4 milhões de bezerros estariam disponíveis para a produção de carne durante o ano (Campos, 1994). A produção desses animais com tecnologia capaz de maximizar a lucratividade poderia aumentar a receita dos produtores ao longo do ano.

Os animais holandeses e seus mestiços apresentam excelente taxa de crescimento na primeira fase de vida (Lucci, 1989). O leite deve ser o principal alimento desses bezerros, entretanto, por ser um produto destinado à comercialização e representar $90 \%$ do custo de produção, sua utilização é restrita a fêmeas de reposição (Signoretti et al., 1995).

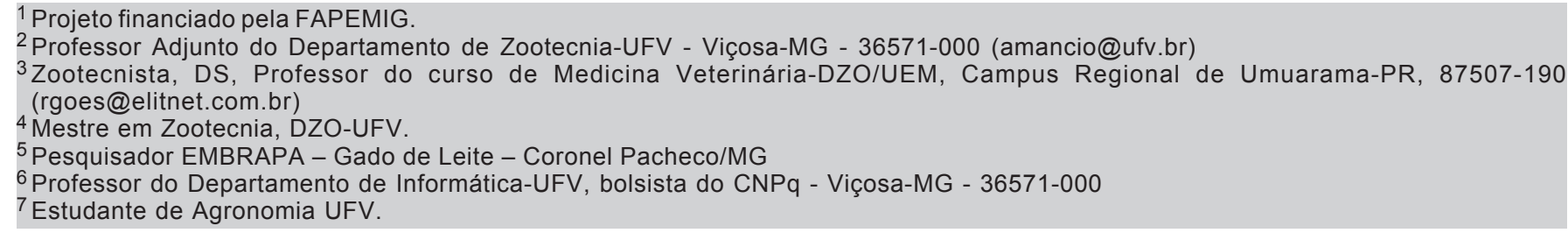


Inúmeros trabalhos foram desenvolvidos objetivando-se estabelecer alternativas de uso de um sucedâneo eficaz, de baixo custo, e que esteja associado a um plano nutricional (Modesto, 2000; Modesto et al., 2002). A utilização de leite ou sucedâneos associados à alimentação sólida pode ser vantajosa a partir da segunda semana de vida, com o intuito de se antecipar o consumo de nutrientes (NRC, 2001).

O colostro, primeira secreção da glândula mamária, é rico em imunoglobulinas, que são essenciais para suprir as necessidades de anticorpos do recém-nascido. Além disso, possui características nutritivas semelhantes ao leite, podendo ser fornecido in natura (NRC, 2001) ou fermentado naturalmente. O processo de fermentação natural foi desenvolvido como uma forma econômica de armazenamento, para se maximizar o uso e minimizar as perdas do colostro, constiuindo-se em potente substituto ao leite (Modesto et al., 2002).

Problemas decorrentes do fornecimento de colostro fermentado, como a diarréia, podem ser atribuídos principalmente ao excesso de acidez $(\mathrm{pH}$ inferior a 4,0), em função do longo período de estocagem. Todavia, a adição de agentes tamponantes, como o bicarbonato de sódio, pode corrigir a acidez (Hodge \& Jenny, 1983; Jenny et al., 1984).

A deficiência energética do colostro durante a estocagem ocorre pela conversão dos açúcares em ácido láctico por processo microbiológico e pode ser solucionada com a adição de óleo de soja, como fonte energética (Modesto, 2000).

Com o propósito de maximizar a produção, o emprego do promotor de crescimento Zeranol em bezerros da raça leiteira entre os 7 e 90 dias de vida proporciona melhor desempenho quando comparado à não-aplicação (Nelson \& Kelly, 1972). A utilização de anabolizantes como promotor de crescimento trouxe novas perspectiva à produção de carne, em virtude de sua ação sobre o desenvolvimento muscular (Souza, 1991). Entre os produtos utilizados, destaca-se o Zeranol, um anabolizante sintetizado a partir da zearalenona - um composto estrogênico extraído do fungo de milho Giberrella zeae. A ação deste composto proporciona maior porcentagem de proteína e diminuição dos teores de gordura da carcaça.

O objetivo neste trabalho foi avaliar o desempenho de bezerros mestiços F1 Holandês x Gir, provenientes de rebanhos leiteiros alimentados com leite integral ou colostro fermentado, associado ou não com óleo de soja, com ou sem o promotor de crescimento Zeranol.

\section{Material e Métodos}

O experimento foi conduzido nas dependências do Setor de Bovinocultura de Leite do Departamento de Zootecnia da Universidade Federal de Viçosa-MG no período de abril a agosto de 1997.

Foram utilizados 40 bezerros F1 Holandês x Gir, com peso médio inicial de $36 \mathrm{~kg}$ alojados em baias individuais de $1,10 \times 1,70 \mathrm{~m}$, dotadas de piso ripado de madeira, com comedouros individuais, de concentrado e volumoso.

Ao completarem 15 dias de idade, iniciou-se o período experimental. À medida que chegaram ao local, os animais foram identificados, numerados, pesados e desverminados, receberam uma dose de vitamina $\mathrm{ADE}$ injetável e tiveram a altura de cernelha e o comprimento torácico determinados. As determinações de altura de cernelha e do comprimento torácico foram feitas semanalmente em todos os tratamentos. Os animais foram abatidos com peso médio de $57,38 \mathrm{~kg}$ aos 60 dias de idade.

Os tratamentos avaliados foram: leite integral (L); leite integral com óleo de soja (LO); leite integral e Zeranol (LZ); leite integral com óleo de soja e Zeranol (LOZ); colostro fermentado (CF); colostro fermentado com óleo de soja (CFO); colostro fermentado e Zeranol (CFZ); colostro fermentado com óleo de soja e Zeranol (CFOZ).

A alimentação foi composta por $3 \mathrm{~L}$ da dieta líquida, fornecida diariamente no período da tarde, por ração concentrada inicial contendo $23 \%$ de proteína bruta fornecida em quantidades crescente até atingir o limite de $1,5 \mathrm{~kg} / \mathrm{dia}$, e feno de capim-tifton 65 (Cynodon spp), disponibilizado à vontade. O leite integral foi oferecido a fresco, após a ordenha da tarde. O colostro, armazenado em tambores de plástico de 60 litros, foi homogeneizado diariamente com fermentação ao natural, durante sete dias, e utilizado em até 28 dias.

Os animais alimentados com os tratamentos $\mathrm{LO}, \mathrm{LOZ}, \mathrm{CFO}$ e CFOZ receberam $45 \mathrm{~mL}$ de óleo degomado de soja e 2,5 $\mathrm{mL}$ de emulsificante à base de lecitina de soja, adicionados à dieta. Ao colostro fermentado, foram acrescentados $25 \mathrm{~g}$ de bicarbonato de sódio por animal, como agente tamponante. O implante do pellet de $36 \mathrm{mg}$ de Zeranol foi feito no início do experimento, via subcutânea, na orelha, nos animais dos tratamentos $\mathrm{LZ}, \mathrm{LOZ}, \mathrm{CFZ}$ e CFOZ. 
Os teores de matéria seca (MS), proteína bruta $(\mathrm{PB})$, cinzas $(\mathrm{CZ})$, extrato etéreo $(\mathrm{EE})$, fibra em detergente neutro (FDN), fibra em detergente ácido (FDA) das dietas líquidas e da ração concentrada foram determinados segundo metodologia descrita por Silva \& Queiroz (2002). O teor de carboidratos totais (CHOT) foi estimado por CHOT $(\%)=100-$ $\mathrm{PB} \%$ - EE\% - MM\% e os carboidratos não-estruturais por $\mathrm{CNE}=\mathrm{CHOT}-\mathrm{FDN}$ (Sniffen et al., 1992). A gordura total do leite integral e do colostro fermentado, associados ou não ao óleo de soja, foi determinada por intermédio de butirômetro. Consta nas

Tabela 1 - Teores de matéria seca (MS), proteína bruta (PB), gordura total (GT) e cinzas (CZ) com base na matéria seca, das diferentes dietas líquidas

Table 1 - Contents of dry matter (DM), crude protein (CP), total fat (TF) and ash, for different liquid diets, dry matter basis

\begin{tabular}{|c|c|c|c|c|}
\hline $\begin{array}{l}\text { Dieta líquida } \\
\text { Liauid diet }\end{array}$ & MS (\%) & $\mathrm{PB}(\%)$ & $\mathrm{GT}(\%)$ & $\begin{array}{l}\mathrm{CZ}(\%) \\
A \operatorname{sh}(\%)\end{array}$ \\
\hline Leite (Milk) & 10,47 & 27,00 & 29,61 & 6,44 \\
\hline $\begin{array}{l}\text { Leite + óleo de soja } \\
\text { Milk + sov oil }\end{array}$ & 10,61 & 29,61 & 39,59 & 6,93 \\
\hline $\begin{array}{l}\text { Colostro fermentado } \\
\text { Fermented colostrum }\end{array}$ & 8,94 & 48,83 & 12,30 & 13,24 \\
\hline $\begin{array}{l}\text { Colostro fermentado }+ \\
\text { óleo de soja } \\
\text { Fermented colostrum }+ \text { s }\end{array}$ & 9,40 & 49,40 & 13,83 & 11,45 \\
\hline
\end{tabular}

Tabelas 1 e 2 a composição das diferentes dietas líquidas e dos alimentos sólidos utilizados, respectivamente.

As sobras das dietas sólidas foram controladas diariamente, determinando-se o consumo total diário por animal.

O delineamento estatístico adotado foi o inteiramente casualizado em um esquema fatorial $2^{3}$, conforme o modelo:

$$
\begin{gathered}
\mathrm{Y}_{\mathrm{ijkl}}=\mathrm{m}+\mathrm{A}_{\mathrm{i}}+\underset{\mathrm{j}}{\mathrm{O}_{\mathrm{j}}+\mathrm{P}_{\mathrm{k}}+\mathrm{AO}_{\mathrm{ij}}+\mathrm{AP}_{\mathrm{ik}}+\mathrm{OP}_{\mathrm{jk}}+} \\
\mathrm{AOP}_{\mathrm{ijk}}+\mathrm{e}_{(\mathrm{ijk})}
\end{gathered}
$$

em que: $\mu=$ constante geral, $\mathrm{A}_{\mathrm{i}}=$ efeito referente à dieta líquida $\mathrm{i}\left(\mathrm{i}=1\right.$ e 2); $\mathrm{O}_{\mathrm{j}}=$ efeito referente à adição de óleo de soja $(\mathrm{j}=1$ e 2$) ; \mathrm{P}_{\mathrm{k}}=$ efeito referente à aplicação do Zeranol $\left(\mathrm{k}=1\right.$ e 2); $\mathrm{AO}_{\mathrm{ij}}, \mathrm{AP}_{\mathrm{ik}}, \mathrm{OP}_{\mathrm{jk}}$, $\mathrm{AOP}_{\mathrm{ijk}}=$ interações entre os efeitos principais; e e (ijk) = erro-padrão, associado à cada observação, pressuposto NID $\sim\left(0, \sigma^{2}\right)$

\section{Resultados e Discussão}

A adição de óleo de soja no leite e no colostro fermentado proporcionou maior teor de proteína bruta (Tabela 1), provavelmente em virtude da inclusão de lecitina de soja, que possui o radical trimetil amina (colina) no terceiro grupamento ligante, elevando o teor de nitrogênio dessas dietas.

Em decorrência das características físico-químicas do óleo de soja e da lecitina de soja, não se obteve

Tabela 2 - Teores de matéria seca (MS), proteína bruta (PB), extrato etéreo (EE), cinzas (CZ), carboidratos totais (CHOT), fibra em detergente neutro (FDN), fibra em detergente ácido (FDA) e carboidratos não-estruturais (CNE) da ração concentrada e do feno

Table 2 - Contents of dry matter (DM), crude protein (CP), ether extract (EE), ash, total carbohydrates (CHO total), neutral detergent fiber (NDF), acid detergent fiber (ADF) and nonstructural carbohydrates (NSC), for the concentrated diet and hay

\begin{tabular}{lcccccccc}
\hline & $\mathrm{MS}$ & $\mathrm{PB}$ & $\mathrm{EE}$ & $\mathrm{CZ}$ & CHOT & FDN & FDA & CNE \\
& $D M$ & $C P$ & $E E$ & Ash & CHO total & NDF & ADF & NSC \\
\hline Concentrado (Concentrate) & 87,32 & 23,21 & 2,92 & 6,92 & 66,95 & 15,08 & 6,8 & 51,87 \\
Feno (Hay) & 91,44 & 10,34 & 1,37 & 8,69 & 79,60 & 78,52 & 35,67 & 1,08 \\
\hline
\end{tabular}


perfeita homogeneização destes componentes com o colostro fermentado. A lecitina de soja possui melhor efeito homogeneizante se adicionada na forma sólida (Campos \& Silva, 1986); neste trabalho, foi administrada na forma líquida, o que pode ter interferido no teor de gordura total das dietas à base de colostro fermentado (Tabela 1).

Os resultados para o consumo total de ração concentrada, durante o período experimental, foram significativos para a interação dieta líquida e Zeranol (Tabela 3). A utilização de Zeranol não promoveu diferença quando se utilizou leite integral. Foi observado maior consumo de concentrado para os animais tratados com colostro fermentado e implantados com Zeranol, que foi $44,23 \%$ superior ao daqueles nãotratados com promotor de crescimento e $132 \%$ a mais do que os submetidos ao leite integral com Zeranol.

$\mathrm{Na}$ Tabela 4 encontram-se os valores médios para o consumo de matéria seca total (feno + ração concentrada). Os animais tratados com colostro fermentado apresentaram maiores consumos de matéria seca, como relatado por Modesto et al. (2002), que não observaram efeito da adição de óleo de soja sobre o consumo de matéria seca total dos animais. O maior consumo dos animais que receberam colostro decorreu da maior ingestão de ração concentrada.

Não houve diferença na associação do leite integral com Zeranol. Entretanto, sua utilização elevou o consumo em $16,46 \%$, quando comparado aos animais não tratados, enquanto os animais tratados com colostro apresentaram aumento de $24,86 \%$. Resultados inferiores na associação de

Tabela 3 - Consumo de ração concentrada $(\mathrm{kg})$ durante o período experimental, de bezerros alimentados com leite ou colostro fermentado, tratados ou não com Zeranol

Table 3 - Effect of feeding with milk or fermented colostrum, with or without Zeranol on intake of concentrate diet (kg), during the experimental period, for calves

\begin{tabular}{lcc}
\hline $\begin{array}{l}\text { Dieta líquida } \\
\text { Liquid diet }\end{array}$ & \multicolumn{2}{c}{$\begin{array}{c}\text { Zeranol } \\
\text { Zeranol }\end{array}$} \\
\cline { 2 - 3 } & Sem (Without) & Com (With) \\
\hline Leite (Milk) & $17,08 \mathrm{Aa}$ & $13,41 \mathrm{Ab}$ \\
Colostro fermentado & $21,57 \mathrm{Ba}$ & $31,11 \mathrm{Aa}$ \\
Fermented colostrum & & \\
\hline
\end{tabular}

Letras maiúsculas iguais na mesma linha e minúsculas na mesma coluna $(P>0,05)$ são diferentes pelo teste $F$.

Means followed by the same capital letters within a row and the small letters within a column $(P>0.05)$ differ by $F$ test. colostro fermentado com Zeranol confirmam os dados de Vandewal et al. (1975), quanto ao efeito negativo de anabolizantes no desempenho de vitelos. Porém, outros estudos confirmam que o uso de promotores de crescimento pode levar ao aumento no consumo de alimentos, em função de mudanças no metabolismo animal (NRC, 1996; Hoffmann, 1998).

Para ganho de peso, não houve interação $(\mathrm{P}>0,05)$ entre os tratamentos. Desse modo, o desempenho dos bezerros nesta fase pode ser estimado por uma equação de regressão linear em função dos dias de avaliação, considerando-se que o desenvolvimento dos animais neste período foi crescente (Figura 1). Os bezerros submetidos aos tratamentos com os dois tipos de dieta líquida apresentaram taxa de crescimento constante e semelhante, comprovando que o colostro fermentado é capaz de promover ganho de peso da mesma magnitude que o sistema tradicional de produção.

Houve interação $(\mathrm{P}<0,05)$ entre a dieta líquida fornecida e a aplicação de Zeranol, para ganho médio diário dos bezerros (Tabela 5). O maior ganho de peso foi observado quando se utilizou o promotor de crescimento associado ao leite. O ganho médio diário de $0,537 \mathrm{~kg} / \mathrm{d}$ foi semelhante ao observado por Biondi et al. (1984), de $0,515 \mathrm{~kg} / \mathrm{d}$, e por Modesto et al. (2002), de $0,569 \mathrm{~kg} / \mathrm{d}$.

Não houve diferença no ganho de peso entre os animais que consumiram colostro fermentado, tratados ou não com Zeranol. Contudo, os altos níveis de proteína dos tratamentos contendo colostro podem ter influenciado os resultados do ganho médio diário.

Tabela 4 - Consumo de matéria seca total (feno + ração concentrada) $(\mathrm{kg})$ de bezerros alimentados com as diferentes dietas líquidas com ou sem aplicação de Zeranol

Table 4 - Effect of feeding with milk or fermented colostrum, with or without Zeranol on dry matter intake (hay + concentrate ration) ( $\mathrm{kg})$, for calves

\begin{tabular}{|c|c|c|}
\hline \multirow[t]{2}{*}{$\begin{array}{l}\text { Dieta líquida } \\
\text { Liquid diet }\end{array}$} & \multicolumn{2}{|c|}{$\begin{array}{l}\text { Zeranol } \\
\text { Zeranol }\end{array}$} \\
\hline & $\operatorname{Sem}($ Without $)$ & $\operatorname{Com}($ With) \\
\hline Leite (Milk) & $26,66 \mathrm{Ab}$ & $31,05 \mathrm{Aa}$ \\
\hline $\begin{array}{l}\text { Colostro fermentado } \\
\text { Fermented colostrum }\end{array}$ & $40,32 \mathrm{Aa}$ & $32,29 \mathrm{Ba}$ \\
\hline
\end{tabular}

Letras maiúsculas iguais na mesma linha e minúsculas na mesma coluna $(P>0,05)$ são diferentes pelo teste $F$.

Means followed by the same capital letters within a row and the small letters within a column $(P>0.05)$ differ by $F$ test. 


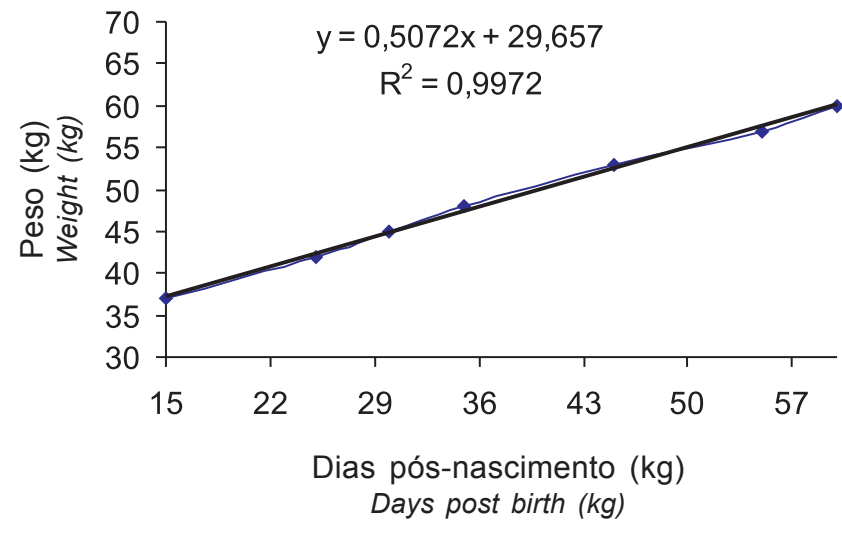

Figura 1 - Regressão do peso dos animais, em função do período experimental.

Figure 1 - Regression on animal weight, according to the experimental period.

Segundo Hall (1977), o alto nível de proteína na dieta influencia negativamente os ganhos promovidos pelo Zeranol, em animais na fase de crescimento.

A média para as mensurações dos bezerros, para a altura de cernelha (AC), no final do experimento, foi de $80,25 \mathrm{~cm}$, inferior à encontrada por Modesto et al (2002), de 84,05 cm. Os animais recebendo colostro fermentado apresentaram a mesma taxa de crescimento que aqueles tratados com leite integral. Não se observou efeito da adição de óleo de soja ou de promotor de crescimento, o que permite inferir que a utilização do colostro fermentado foi suficiente para garantir a taxa de crescimento, uma vez que a mensuração da altura de cernelha apresentou correlação positiva com o desenvolvimento da estrutura óssea do animal (Signoretti et al., 1995).

$\mathrm{Na}$ Tabela 6 constam os valores médios para a altura de cernelha, onde observa-se interação entre dieta líquida e promotor de crescimento.

O efeito do Zeranol foi maior nos animais alimentados com leite integral. A utilização de apenas colostro fermentado proporcionou maior altura de cernelha, semelhante à combinação de leite integral e Zeranol (Tabela 6), o que demonstra a eficácia do colostro fermentado em promover a altura de cernelha.

O NRC (1988) relata que, com o fornecimento de altos teores de gordura em sucedâneo, eleva a deposição de tecidos adiposo na carcaça, mas sem fornecer a energia prontamente disponível para a deposição de tecidos muscular e ósseo. Por isso, a presença
Tabela 5 - Ganho médio diário $(\mathrm{kg} / \mathrm{d})$ dos bezerros tratados com leite ou colostro fermentado, associados ou não à aplicação de Zeranol

Table 5 - Effect of feeding with milk or fermented colostrum, with or without Zeranol on average daily gain $(\mathrm{kg} / \mathrm{d})$, for calves

\begin{tabular}{|c|c|c|}
\hline \multirow[t]{2}{*}{$\begin{array}{l}\text { Dieta líquida } \\
\text { Liquid diet }\end{array}$} & \multicolumn{2}{|c|}{$\begin{array}{l}\text { Zeranol } \\
\text { Zeranol }\end{array}$} \\
\hline & Sem (Without) & Com (With) \\
\hline Leite & & \\
\hline Milk & $0,389 \mathrm{Ba}$ & $0,537 \mathrm{Aa}$ \\
\hline $\begin{array}{l}\text { Colostro fermentado } \\
\text { Fermented colostrum }\end{array}$ & $0,494 \mathrm{Aa}$ & $0,476 \mathrm{Aa}$ \\
\hline
\end{tabular}

Letras maiúsculas iguais na mesma linha e minúsculas na mesma coluna $(P>0,05)$ são diferentes pelo teste $F$.

Means followed by the same capital letters within a row and the small letters within a column $(P>0.05)$ differ by $F$ test.

Tabela 6 - Altura média $(\mathrm{cm})$ da cernelha dos bezerros ao final do experimento (ACF), para a interação dieta líquida $x$ Zeranol

Table 6 - Effect liquid diet $x$ Zeranol on average withers (cm) height, for calves at the end of the experiment

Dieta líquida

Liquid diet

Zeranol

\begin{tabular}{lcc} 
& Sem (Without) & Com (With) \\
\hline Leite & $84,40 \mathrm{Bb}$ & $85,75 \mathrm{Aa}$ \\
$\begin{array}{l}\text { Milk } \\
\text { Colostro fermentado }\end{array}$ & $85,70 \mathrm{Aa}$ & $82,60 \mathrm{Bb}$ \\
Fermented colostrum & &
\end{tabular}

Letras maiúsculas iguais na mesma linha e minúsculas na mesma coluna $(P>0,05)$ são diferentes pelo teste $F$.

Means followed by the same capital letters within a row and the small letters within a column $(P>0.05)$ differ by $F$ test.

do agente anabólico pode influenciar o direcionamento de energia para a deposição de tecidos estruturais.

Assim como a altura de cernelha, a circunferência torácica é indicador do grau de desenvolvimento do animal. Neste estudo, o desenvolvimento torácico não apresentou efeitos com a utilização de óleo de soja ou do Zeranol, com média final de $88,19 \mathrm{~cm}$, inferior à apresentada por Modesto et al. (2002), de 90,79 cm. Os animais tratados com colostro fermentado apresentaram taxas de crescimento semelhantes aos tratados com leite integral. Não foram observadas diferenças $(\mathrm{P}>0,05)$ para o comprimento torácico, que apresentou média de 11,06 cm (Figura 2). 


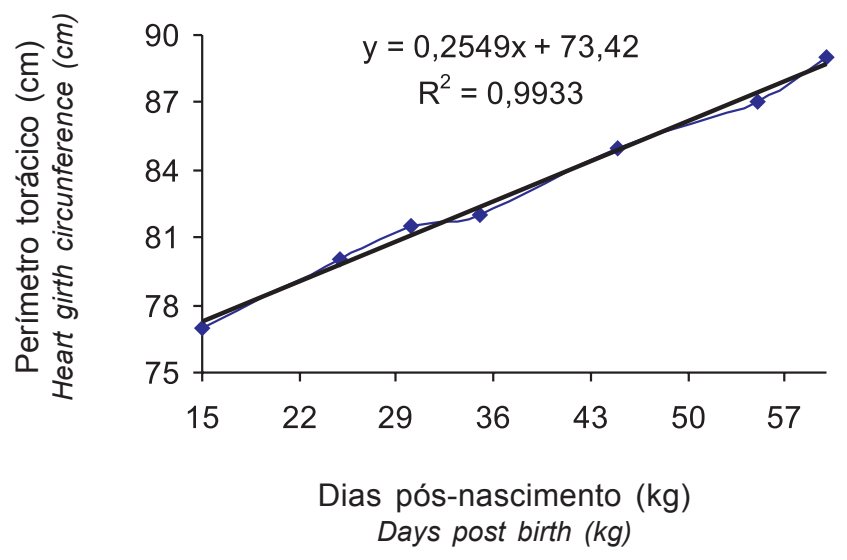

Figura 2 - Regressão do perímetro torácico dos animais, em função do período experimental.

Figure 2 - Hearth girth circumference of calves, according to the experimental period.

\section{Conclusões}

O colostro fermentado promoveu maior consumo de ração concentrada e, conseqüentemente, de matéria seca e de proteína bruta que o leite integral.

$\mathrm{O}$ desenvolvimento dos bezerros foi crescente e semelhante quando submetidos às dietas líquidas com leite integral ou colostro, com ou sem a adição de óleo de soja ou Zeranol, como pode ser observado no ganho de peso, na altura de cernelha e na circunferência torácica.

\section{Literatura Citada}

BIONDI, P.; SCOTT, W.W.; FREITAS, E.A.N. Criação e produção de bovinos machos de raça leiteira para corte. Zootecnia, v.22, n.1, p.27-34, 1984.

CAMPOS, O.F. Estratégias de utilização do bezerro de rebanhos leiteiros para a produção de carne. Coronel Pacheco: EMBRAPA/CNPGL (Subprojeto - DPD), 1994. 15p.

CAMPOS, O.F.; SILVA A.G. Fontes alternativas de proteínas no sucedâneo de leite para bezerros. Pesquisa Agropecuária Brasileira, v.10, n.21, p.1089-1099, 1986.

HALL, G.A.B. Zeranol, anabólico para ruminantes: uma revisão. Revista da Sociedade Brasileira de Zootecnia, v.6, n.1, p.60-83, 1977.

HODGE, S.E.; JENNY, B.F. Performance of calves fed preserved colostrum with sodium bicarbonate added at feeding. Journal of Dairy Science, v.66 (supl. 1), p.256, 1983.

HOFFMANN, B. Critical assessment on the use of anabolic hormones also exhibiting sex-hormone-like activities in ruminant production. In: REUNIÃO ANUAL DA SOCIEDADE BRASILEIRA DE ZOOTECNIA, 35., 1998, Botucatu. Anais... Botucatu: Sociedade Brasileira de Zootecnia, 1998. p. 9-34.
JENNY, B.F.; HODGE, S.E.; O'DELL, G.D. et al. Influence of colostrum preservation and sodium bicarbonate on performance of dairy calves. Journal of Animal Science, v.67, n.2, p.313-318, 1984

LUCCI, C.L. Bovinos leiteiros jovens - nutrição, manejo, doenças. São Paulo: Nobel, 1989. 371p.

MODESTO, E.C. Avaliação de efeitos de dietas líquidas para bezerros desmamados precocemente e estudo anatômohistológico da mucosa do abomaso. Viçosa, MG: Universidade Federal de Viçosa, 2000. 83p. Dissertação (Mestrado em Zootecnia) - Universidade Federal de Viçosa, 2000.

MODESTO, E.C.; MANCIO, A.B.; MENIN, E. et al. Desempenho produtivo de bezerros desmamados precocemente alimentados com diferentes dietas líquidas com utilização de promotor de crescimento. Revista Brasileira de Zootecnia, v.31, n.1 (suplemento), p.429-435, 2002.

NATIONAL RESEARCH COUNCIL - NRC. Nutrient requirements of beef cattle. 7.ed. Washington: National Ademy Press, 1996. 242p.

NATIONAL RESEARCH COUNCIL - NRC. Nutrient requirements of dairy cattle. 6.ed. Washington, D.C.: Academic Press, 1988. 158p.

NATIONAL RESEARCH COUNCIL - NRC. Nutrient requirements of dairy cattle. 7.ed. Washington, D.C.: Academic Press, 2001. 381p.

NELSON, M.L.; KELLY, J.W. Ralgro implant effect of young Holstein steers. Journal of Animal Science, v.35, n.11, p.113-129, 1972.

SIGNORETTI, R.D.; CASTRO, A.C.G.; COELHO DA SILVA, J.F. et al. Utilização de farelo de gérmen de milho no concentrado inicial de bezerros de raças leiteiras em sistemas de desaleitamento precoce. Revista Brasileira de Zootecnia, v. 24 n.5, p.841-851, 1995.

SILVA, D.J.; QUEIROZ, A.C. Análise de alimentos (Métodos químicos e biológicos). Viçosa, MG: Universidade Federal de Viçosa, 2002. 239p.

SNIFFEN, C.J.; O'CONNOR, J.D.; Van SOEST, P.J. et al. A net carbohydrate and protein system for evaluating cattle diets: II-Carbohydrate and protein availability. Journal of Dairy Science, v.70, p.562-577, 1992.

SOUZA, F.A. Anabolizantes: aplicação, problemas e controle de inspeção. Belo Horizonte: Universidade Federal de Minas Gerais, 1991.40p. Monografia (Curso de Aperfeiçoamento em Ciência, Inspeção e Tecnologia de Alimentos de Origem Animal) - Universidade Federal de Minas Gerais. 1991

VANDERWAL, P.; BERENDE, P.L.M.; SPRIESTMA, J.E. et al. Effect of anabolic agent on nitrogen retention of calves. Journal of Animal Science, v.41, n.3, p.986-991, 1975. 